\title{
Organizational Skills in Perspective of Vedanta
}

\author{
Dr. Vidhu Gaur \\ Assistant Professor, Management Development Institute, Gurgaon
}

\begin{abstract}
To keep any organization dynamic, healthy, and productive the managerial personnel must have certain special personality traits and capacities. They should be the source of creative ideas. They should be conscious of the desires, aspirations, needs, and problems of their community, and should have the ability to dispassionately look at, understand and evaluate events and people not only from the material point of view, but from the psychological and spiritual points of view as well. They must have an insight into the deeper aspects of human motivation in order to harness all the potentialities of the employees, both for the individual's growth and the growth of the organization. Above all, they must know the technique of right action through which they can prevent dissipation and disintegration of their own personalities. If we view business enterprise in the perspective of Vedanta, the practice of management will acquire a new complexion and it will no longer be a purely objective exercise to achieve external results. It will concern itself equally with the subjective aspect of individuals. Ancient insights and modern-day management theory are combined now a days and it is practically happening in large organizations like Google where eastern wisdom is changing western business.
\end{abstract}

Keywords: Equanimity, Thought Level, Gut Level, Personal Planning Model, swabhava

\section{Introduction}

Management deals with people. As is clearly evident, the role of an employee in an organization is pivotal. This cannot be replaced by any kind of technology, method, system or resources. If productivity of an industry has to improve, the productivity of the men associated with the industry has to improve. Successful manager needs knowledge of all factors that he has to manage and all that is beyond, which directly or indirectly impinge on his micro environment. Today, there is an intense need to develop a comprehensive personality capable of blending outer and inner self so as to develop the goals and values of business management. Real time management lies in appreciating the significance of both the cognitive and the operational area in which tasks are undertaken. It is said: "The job of leadership today is not just to make money, it's to make meaning." In the old days, most of people were content to have a job that simply paid the bills. But now, they crave so much more in the work. They want fulfillment, creative challenge, growth, joy and a sense that they are living for something more than themselves (Usha 2012).

It is quite interesting to note that though every employee in an organization works with similar materials, machines and tools, yet the level of individual performance do vary in great proportions. It indicates that some sort of relationship does exist between an employee's performance and his mind-set i.e. his attitudinal and personality characteristics. The level of performance of a worker on a job is a direct outcome of his motivation to perform the job efficiently. However, the biggest problem faced by employees is not in the 'outer space' but in the 'inner space.' It is this relationship between the individual's attitudinal and personality characteristics. A person's performance is an index of his mind that helps to innovate, improve, and perform better. It is the 'inner matter' that matters the most. Someone has rightly said: "without good people there is no business, and the business is only as good as the people it employs." The mind is the seat of self-motivation.

Real efficiency does not come from the head but emerges from the heart. What is uttered from the heart alone succeeds in winning the hearts of others. This can be well understood from the example of habitual smokers. On every pack of cigarettes, it is clearly written, 'Cigarette smoking is injurious to health,' yet millions of people continue to smoke day-in and day-out. Somewhere, somehow, they have developed the notion that it is not going to harm them or that it may not be true for them, though it may be true for others. There is a great deal of difference between being aware about something at the 'thought level' and feeling or realizing it at the 'gut level.' Research in psychology has proved that awareness at the 'thought level' alone doesn't bring about any change in the behavior of the person. It is only when one starts feeling or realizing the situation that one begins to change. Training programs and seminars to spread awareness mostly remain at the 'thought level' level. Employees, therefore, never feel the need to enhance efficiency. An individual who thinks productivity is necessary keeps advising others to improve but the one who feels its necessity actually starts doing it and this is the difference. But the question is how to make employees feel about it. As the famous saying goes, 'Only the person whose shoe pinches can realize the pain.' If employees are to be made to feel the 'pinch,' the management must place the employees in their shoes. This is possible when the management involves the participation of its employees in the problem-solving and decision-making process at various levels. The best teacher in the world is one's own experience. Such an experience will make the employees feel the need to enhance efficiency (Sukh 2001). 


\section{Personal planning model}

The challenge to various organizations is to provide a framework for people to understand their own journey through change so that they can best contribute to the organization. The way to plan and re-engineer change in one's own life is done on the basis of a model very identical to the corporate planning model. The organizational planning model is like the compass or a road map that gives a direction to the people to determine the way they have to navigate and achieve their vision. Similarly, self-management also provides a personal planning model for self-development. It includes the identical steps as the organizational planning model to develop a clear focus and reorganize from within. The organization's direction is determined on the basis of the facts obtained from the organizational SWOT analysis so as to move into the future and reach insights which help to redefine the mission, vision statements and the values (Sharma 2001).

Very similar to this planning model, self-management personal model becomes the road map for selfdevelopment and in leading a meaningful life of fulfillment and satisfaction. But, it is important to have the right mental state when planning for our future. We should be free from all preconceived notions about the self and the things which are influencing us. The best mental position is that of a detached observer. In the state of being a detached observer, we are able to see ourselves and the influences in the way of our life. We have to be cautious of them so that they don't distort the judgment and discrimination.

The key to stability is balance. The personal planning process involves two major areas to balance: firstly, the balance between the past and the future and secondly the balance between hard thinking and soft thinking i.e., to be analytical, logical and rational but at the same time be intuitive, creative and emotive. In order to play a leadership role, we must be able to bring about significant changes in our own mission, vision and values. The important principle of leadership is that the leader is someone who is easily able to exercise both thinking styles, i.e., hard and soft according to the need. Many people lack this balance, some are too emotional and others are too rational. A leader's mind features a fine balance of both (Gaur 2012).

\section{Vedantic methods in organizational skills}

Rudeness at work is contagious. An article appeared in Times of India, New Delhi on dated Sept. 1, 2015 at page 19 says that a rude workplace culture is nasty for employees, but it can also have a negative effect on the success of their employer too. A new study by Trevor Foulk at University of Florida says that rudeness has an incredibly powerful negative effect on the workplace and while experiencing rudeness they perform worse, they are less creative, and they are less helpful with coworkers. It is the need of the present modern era that suitable inner qualities are to be developed to eradicate rudeness etc from the workplaces. The aim of organizational skills is to learn how to better manage the inner organization as a means for more effective leadership of the external organization and develop a practical self-management plan so that one can get the best out of oneself and from others too. If we view business enterprise in the perspective of Vedanta, the practice of management will acquire a new complexion and it will no longer be a purely objective exercise to achieve external results. It will concern itself equally with the subjective aspect of individuals. What a business career does for a manager will be as important as what he does for the business. One who has acquired a realistic vision of the totality finds himself rising over narrow, short-term, individualistic motives that generally drive human beings. He is no longer swayed by the external temptations of tangible, material success for he knows how insignificant they are in terms of eternity. The larger vision encompasses good of mankind and the welfare of society. Few Vedantic issues related to modern organizational skills are discussed here-under.

\subsection{Keep the mind discerning and alert}

Indolence, lethargy is man's greatest enemy. It makes a living body equivalent to a dead one. How is it possible for the body to run by itself and do useful work, when the owner refuses to be active, courageous and industrious? People do not look at their own shortcomings, nor do they make any attempt to improve on them. As a consequence, though they somehow drag on a monotonous existence, in absence of habit of perpetual industriousness, hardly any achievement is made which could be called creditable. After overpowering body, indolence also engulfs mind in the state of negligence (pramad). When it happens, one becomes indifferent to the consequences of regression and hardly ever feels an urge for improvement. Because of this inertia the outlook of the person becomes narrow, giving rise to a state in which neither there emerges an urge to learn new things nor for formulating plans for a betterment. The lazy and indolent person somehow continues to pass uneventful day in this state of misery and undesirable concepts in mind.

Apart from the above class of people, one comes across a large number of persons having yet another distorted concept. They remain in a constant delirium of being a victim of misfortunes, for which they are found ever irritable. Dissatisfaction with the environment produces indignation which has a profound effect on everyday life. In such an environment, little scope is left for thinking about ways, means and directions for progress.

Yet another big obstacle in progress, which deprives man of more than half of his energy, is greed, 
desires and their satiation for which there is no end. Sex is one of them. Copulation is only a small fraction of sexual indulgence which gets satiated within a few moments but the related sexual obscenity, however, continues to dominate the mind as vulgar imageries now and then and does not let it conceptualize anytime utilitarian. Similar is the craving for wealth which does not ever get weakened at any limits of acquisition. The set of lofty ambitions too has the same effect on man, which continues to be a mania of exhibitionism of superiority and a rat race for showing one's greater authority by acquisition of more and more powers. Days and nights of such persons are spent in perpetual restlessness. We are aware of the state of mind of candidates contesting an election. The forgoing are states of troubled mind which apparently find an expression in worry, despair, apprehension, fear, anger, fits of temper, tension and so many other forms. The root cause for these psychic aberrations may be grouped broadly under four heads namely (1) Enmity (2) Sexual indulgence (3) Satiation of desires and (4) Utopian lofty ambitions. The more one suffers from these maladies, the greater he would remain in state of insensibility and irresponsibility like a drunkard under the influence of hard liquor. The mind of such a person would appear sick and the body as one who remains without meals on imposed fast. In other words persons suffering from laziness, lethargy, and lassitude are considered weak and incompetent for any significant achievement. If in addition they also become victims of selfishness, sensuality and erratic lofty ambitions, it should be considered as a compounded misfortune, since such persons are unable to organize even their personal life, they find it all the more difficult to plan for a higher level of progress. They are also unable to seek avenues for earning distinction in society by participating in schemes of social welfare. There is only one way to get rid of these maladies and that is to cast away the elements of incongruities and imbalance from body and mind and maintain such an equilibrium which could help in cultivating prudence by deep penetration, so that it becomes possible to seek amicable solutions. Such is the frame of mind necessary for seeking and moving on the path of progress.

For making proper use of physical and mental gifts of the creator in a right manner, it is necessary to remain in a cheerful state. The mind should always be kept discerning and alert. It is necessary to exercise selfrestraint, develop discernment and thereby be fully aware of future consequences of actions. In one word, this state of mind is known as talent (pratibba). Only talented persons on the basis of existing facts and manage to govern their own as well as other's activities to establish a well-organized system for alleviation. The mentally indolent persons associate with any scheme of work only in the initial stages, and postpone the remaining part for indefinite time in future, when they expect someone else to take up their responsibility. Consequently, the little accomplishment which they make in the initial stages also does not bring them credit and instead makes them an object of ridicule and disgrace. Whatever assignment responsible persons undertake, they look after all its aspects and maintaining interest and enthusiasm from beginning to an end give a proof of their total involvement and efficiency.

For cultivation of talents an acutely discerning mind is required. A beginning is made by taking care of the twin machinery of body and mind. Since the body is expected to perform significant tasks for a long period throughout life, like a machine it should be 'operated' in such a way that it continues to work without 'breakdowns' and the efficiency of performance is maintained. It requires merely a watch on retention of proper balance in matters related to food, rest and physical activities. Care of these three variables related to body ensures perfect health. The first step towards cultivation of talents is, therefore, taken by giving emphasis to preservation of health. Next step is the thought process (chintan), which is kept under harness. To arrive at right conclusions and thereafter for taking appropriate decisions, it is necessary to keep the mind free form stress and excitement since it is a quiet mind which makes pragmatic schemes and until a well balanced plan is formulated, it cannot be implemented in a manner indicative of the efficiency and excellence of the person doing it. With the organization of functions of body and mind, one covers the initial half of success in external facets of life or in the matters of world without (Sharma 2010).

\subsection{Basic Principles for Development of Organizational Skills}

Area of one's personal influence depends on management of three variable physical entities namely: body (behavioral pattern), contemplative attitude (chintan) and "Resources" at command successively. With the help of these three attributes men may become great and make big achievements. Personal characteristics (guna), behavioral pattern (karma) and pattern of transactional response or nature (swabhava) of the person also reflect the same.

Refinement of guna, karma and swabhava produces miraculous results by virtue of which enmity is quelled and indifference transformed into friendship. A vicious person tends to reduce the number of supporters, admirers and associates and faces an increasingly bigger number of adversaries. Such persons have nothing to gain. Fire initially destroys things in its neighborhood and then spreads beyond. The same is true about vices. Apparently they appear incapable of doing much harm to the individual, but indirectly create an environment of antagonism and distrust which does not help anyone (Sharma 2010). 


\subsubsection{Indiscipline of speech}

Indiscipline of speech is the most dangerous enemy of man. The habit of downgrading or condemning others by unjust criticism (ninda) and back biting (chugali) creating an environment of antipathy, malice casts doubts on the trustworthiness of the person in keeping secrets. Persons prone to those habits are so much undependable that even their own kiths and kin hesitate to trust them about their intimate personal matters.

The adverse consequences of anger and agitation (avesh) or retaliatory emotional outburst become immediately visible. Within moments of speaking bad words, the counteracting reply of the adversary is retorted more forcefully. At times, the effect of bad words is catastrophic. It becomes a permanent cause of enmity and in course of time inflicts serious harm to the speaker because of reprisals. The sarcastic words spoken by Draupadi against Duryodhan, in course of time became the causative factor for the widespread devastation in the war of Mahabharata.

Intemperate speech and insulting behavior are products of combined reactions of personal ego and disrespect for the other person. Both are equally powerful in producing dangerous consequences. The speech emanating from combination of these two factors may on the face of it appear inconsequential, but at times produces an unbridgeable chasm of hatred between persons.

Words which are spoken with civility and humility are always full of politeness and pleasantry. They have enough power to pacify tempers. Soft spoken persons have often been found bringing together enemies and beginning a new chapter of goodwill. Discarding some bad habit and converting it into a good one requires only a few days practice with caution. Carefully chosen words, spoken calmly and humbly, and keeping the dignity of other person in view can be seen producing instant favorable and pleasant reactions. The art of speaking with civility, humility and pleasantry needs only few days practice (Sharma 2010).

\subsubsection{Lack of self-restraint (asamyams)}

Lack of self-restraint is yet another name for disorderliness of body and mind. It may also be seen as a natural resistance to discipline and a tendency towards recklessness. Such traits make a person personally and socially irresponsible and create far-reaching disastrous consequences. Absence of moderation may also be viewed as a habit of dispensing available useful resources for meaningless and unproductive schemes. There are four types of lack of self-restraints (asamyams): Indriya asamyam i.e. indiscipline of senses, Samaya asamyam i.e. indiscipline of time, Vichar asamyam i.e. indiscipline of thinking habit, and Arth asamyam i.e. indiscipline of resources (wealth). These are like leaks in the vessel of human existence from which significant powers bestowed by God continue to drain continually. When these leaks are sealed the powerful emanations of energy emerging from within the self and showering like divine grace from above make anyone competent and capable of performing extraordinary feats (Sharma 2011).

\subsubsection{Indriya asamyam}

It is found that men at large tend to weaken their health by over indulgence in savor. Such persons meet with untimely death on account of infirmity and sickness. A control over tongue and organ of sensuality preserves the competence of body and makes mental faculties acute and sharp. Management of resources must be judiciously carried out by following simple living and high thinking. Following the average living standards of one's countrymen anyone can live happily and satisfactorily with honest means of earning.

\subsubsection{Samaya asamyam}

Time and life are not inseparable. If every moment of life is considered as an invaluable gem and utilized for a fruitful objective, each one of us can achieve many times more than what is normally possible in one's life-time. Busy persons have no time to think about mischief, nor there appear for them any possibility to learn evil habits in bad company.

\subsubsection{Vichar asamyam}

Powers of immense potentiality is hidden in 'ideas' or thoughts (vichar). A habit of continuous conceptualization of high aspirations and great utilitarian gradually builds up a background for an all-round progress. Positive thinking prepares the ground for interaction and direction needed for success and provides avenues for availability of resources. The four types of indiscipline mentioned earlier deprive man of mummeries inborn capabilities. While safeguarding them one protects the invaluable celestial treasures bestowed by God. Generally, establishment of any organizational skill requires training in some workshop, industrial establishment, administrative department or business organization. This facility may not necessarily be within the reach of an aspirant, beside, even if this arrangement is available it does not necessarily ensure availability of requisite resources and assistance. Keeping these extraneous constraints in view, the easiest way is to practice organization of one's own self to make it adaptable to any environment. One can have full control over one's own body. With a little pressure of will-power the body can be bound in discipline and one can get an access to the fountain head of strong health and long life.

\subsubsection{Arth asamyam}

If the tendency of extravagance is curbed, even with limited earnings one can make an appropriate budget and live a happy and contented life. Extraordinary success can be obtained in matters pertaining to qualification, 
wealth and resources if time is not wasted,. One has full freedom to generate one's own ideas independently. This invaluable natural capacity, if not squandered recklessly, can be used for some creative activities and with it anyone can achieve unprecedented success for desired objectives.

It may be difficult to persuade advice, support or reform someone else, but in one's own reformation and improvement, there can hardly be any other obstacles than lack of will or power of determination. With courage and farsightedness one can upgrade not only physical and mental efficiency, but also improve virtues, action and behavior (guna, karma and swabhava). It is very much possible to change or reform one's confirmed habits. The environment in which one prefers to live is one's own personal choice. Just like the voluntarily chosen substandard environment of the past which became responsible for the present misery, one can also select a superior motivating milieu for progress in future. Close transactions with ethically elevated persons together with a refined environment open umpteen possibilities for progress and up- gradation in life.

Systematic arrangement of a person's articles is the first lesson in organization of self. The articles of use should be treated as study-notes for examination papers which are required to be kept and examined carefully. Any indifference towards them would make them appear substandard and irrelevant and they would lose their utility before time. On the contrary, given due importance and orderly maintained, they provide instant useful service by commensurate return for the care taken. Systematically arranged articles reflect on the mental status of a person. They create an impression that the owner is civilized, cultured and a man of taste. On the other hand, haphazardly thrown articles indicate that the person is unsystematic and raw by the norms of a civilized society. It is irrelevant whether such an individual is wealthy, well educated, or otherwise. To sum up, first lesson in civilized living teaches us to keep household and other articles of use tastefully in a planned and systematic manner. Once this much is achieved, it is understood that significant lesson has been learnt in organizational skills. This process may also be considered as learning primary alphabets of spirituality. Only a disciplined and organized person can hope to become a successful spiritualist (Sharma 2010).

\section{Developing Organizational Skills}

Each being on this earth aspires to be happy and for this purpose is found engaged in various types of activities. Ordinary persons with lowly bent of mind remain engaged in seeking comforts for their physical body only. They spend their time and energy in satiation of desires by eating savory food, wearing the best possible clothes, seeing pleasant sights and things and satisfying carnal desires. Fashions and body ornamentations too are carried out for the same purpose. Others go a step further and are tempted with loftier colorful day-dreams of becoming highly affluent, by acquiring wealth and property and earning titles and status to establish their superiority in the society. People enter into various types of competitions to prove their greater efficiency, competence or prosperity and on achieving success look down contemptuously at others. While contesting an election, the candidates are less interested in social service than in demonstrating their political supremacy. Showmanship in ambitious persons induces them to publish their names in newspapers, take important seats during public functions and even undertake pilgrimages to demonstrate their superlative faith. Expensive family and community feasts are held mainly to advertise personal affluence. It is much easier and takes lesser time and energy to find minimum means of livelihood, but man is found ever busy in demonstrating superiority over others. Man spends most of his life, time, energy and efficiency in acquiring property and resources for such one-upmanship only (Sharma 2010).

\subsection{Cultivation of a High Ambition}

Harboring high ambition is a natural human trait. This world is full of great men each excelling the other in status. Even with the best of effort, one would find one's own achievement insignificant in comparison to these men. Besides, one's enthusiasm is sustained only up to the moment the desired thing or status is achieved. The euphoria of achievement is also momentary. Thereafter one finds it difficult even to retain the burden of additional responsibility for retaining the acquired status. Prior to marriage, one makes castles in the air about the virtues of the would be spouse, but not sooner the heavy responsibility of looking after the family falls on the shoulders, one realizes that the conveniences of married life are far lesser than its complexities. In the rat race of supremacy, the leaders find it difficult to maintain their lead. Their success invites jealous schemers, who try to deprive the former of their advantage by hook or crook. The happiness so achieved and fame are also short-lived. In the world that has time to remember other's achievements, when it is not possible to retain the memory of even one's own past?

Serious contemplations on such aspects have made philosophers arrive at the conclusion that high ambitions for minor mundane things do not bring one lasting credit. They regard them as childish fantasies and advise the thinkers who are interested in leading a meaningful life, to avoid entering this labyrinth of menial desires. There is no wisdom in losing one's energy in return for false sense of prestige. The process of each human endeavor follows a definite course. It begins with an ambition. Each new ambition gives rise to energy and motivation for a continuous effort for its fulfillment. Although an ambition in itself means beginning of 
ultimate success, it must also be kept in mind that the ambition must not relate to small achievements and such goals should also provide an everlasting social recognition as well as self-satisfaction. Lack of wisdom misleads people to elect high ambitions for a counterproductive objective which instead of success brings about only discredit.

The highest level of ambition can only be one that is to develop one's own personality to such an elevated level so as to be able to guide others as well to wares excellence. This is in fact the true leadership. Other so-called leaders, who only play the role of leadership on the stage of the world, deceive themselves in the euphoria of momentary, cheap public acclamation. For this little gain they make tremendous efforts and spend up all of their valuable energy. Had they utilized their capacity for the welfare of others, they would have become so honorable in the society that people would have praised and felt proud in following their example.

Apparently, by 'service' we mean helping the deprived and alleviating the sufferings of unhappy persons; contributing to the upliftment of downtrodden; sympathizing with those in distress and arranging resources for the have-nots. All these acts of service to humanity are recommendable and beneficent to the doer and also essential ingredients of a true religion. As a human being, it is our bounden duty to share our resources of comfort and happiness with the fellow beings that are not so well off. Each and every member of this large family, having faith in human values, is advised to incorporate these acts of service in daily life (Sharma 2010).

\subsection{Seva Sadhana}

A more significant concept of 'service' (Seva Sadhana), is known as Dharma i.e. shouldering the responsibility of betterment of society. It involves undertaking a firm resolution and determined perseverant action to provide guidance for changing the chaos prevalent in the society into order and transforming its rawness to a culturally evolved system. Strictly speaking, this is the real 'service' to humanity. This is the foundation on which the structure of personal and community progress is erected. The sufferings of the masses are not so much aggravated because of lack of resources, as due to absence of opportunities for seeking avenues of progress and peace. The highway to material and spiritual rejuvenation of humanity is built by those persons, who are able to provide this much-needed guidance. Saints (sadhus), Brahmans (persons totally dedicated to service of humanity irrespective their lineage or status), Purohits (priests) and Lok Sevi (social workers) earn the respect and faith of the common man for the exclusive reason that they make life-long endeavors for leading the masses on the way to greater excellence, in which they succeed because of their perseverance. Such guides of humanity are regarded as Rishi Kalp and are counted amongst the Bhusurs (Angles on earth). Once upon a time in the bygone Golden Age of Humanity (Satyug) majority of people living on this earth belonged to the above class and consequently then an environment of peace and prosperity was ubiquitous. The few available resources were being shared with cordiality, a spirit of mutual faith and cooperation prevailed and thus heavenly environment was created. It was due to high level of compassion, thinking and idealistic activities that angelic traits were seen in the mortals. Today, when humanity is on the brink of disaster, there appears a dire need of such guides. Because of absence of such persons the entire social fabric is threatened with problems and adversities. Had the talented amongst the thinkers and the wise in the society followed the ancient tenets of Brahmanism and used their pen, voice and upright character for transmuting the prevalent backwardness into an all round progressiveness, man would have been much more happier and prosperous. This entire process could be called an endeavor for Cultural Revolution. This is in fact the real domain of religion and spirituality.

Persons seeking entry into this domain are also advised to avoid aspiration for Lokeshna (public recognition) besides keeping under control traits of greed, infatuation and family attachments. Generally, the socalled social workers are often found vehemently confronting each other, to establish themselves as leaders in public eye. On account of such attitudes the entire institution of 'social service' falls in disrepute and people look down upon it with suspicion, since such persons only pretend to use it as a platform for human welfare. The one reason for disintegration or demolition of many public organizations has been cliques engineered by overambitious persons for proving their supremacy over their associate workers by downgrading the latter. Keeping such an unwelcome eventuality in view, one desirous of entering the field of social service should adopt total humility of behavior in advance. It is desirable to cultivate a firm attitude of mind in which credit for the endeavor leading to achievement is given to other associates while regarding one's own self as an insignificant volunteer contributing one's full might for the cause. One who develops such a bent of mind is always held in highest esteem by the masses, irrespective of working in the forefront or at backstage (Sharma 2010).

\subsection{Concept of Vyavasthapak}

In administrative systems in this world, the manger holds the most elevated position. Everyone somehow looks after one's own affairs but only those persons are considered indispensable, which having a wider perspective take care of all aspects of relevant system, establish the framework and coordinate the activities. In establishment the General Manager commands highest authority. During the British rule in India, the topmost administrative officer was known as Governor General. The word governor means 'Vyavasthapak' (the one who coordinates 
the activities of the systems). Vyavasthapak is the person who knows how to coordinate one's personal activities as well as the activities of the system under control. The status of such a person is highly dignified and its utility unquestionable. The success of industries, business houses, community development and public schemes depends only on such individuals. Characteristics of a good Vyavasthapak are: Softness of speech, Proper structuring of time, No humiliation, No strong likes and dislikes, Intolerance against weakness and undesirable traits, and Equanimity.

\subsubsection{Softness of speech}

Those having a high ambition to achieve success in establishing orderliness in a small or large family should make a beginning by doing so for their own self. The foremost virtue to be imbibed for this purpose is softness of speech. Soft words win over even opponents whereas harshness of speech and raw behavior of uncivilized persons though not harming physically, antagonizes all coming in contact. The latter have few friends and many enemies and generally people avoid meeting such persons.

Softness of speech does neither mean flattery nor statement of falsehood. One need not give false assurances of assistance. Such a practice pleases all but ultimately brings discredit to the person branding one as liar who never means what is being said. Hence sweetness of speech must also be associated with frankness and truth. With a little tract and humility, one can pleasantly express one's helplessness and make the other person understand without causing any annoyance that the situation is beyond former's control. This is how the culture of verbal interaction is developed.

\subsubsection{Proper structuring of time}

Proper structuring of time is the second characteristic of a good manager. One who is unable to utilize one's own time appropriately according to priorities and spends routine haphazardly does not succeed in convincing others about the value of time. Discipline is a multi-dimensional virtue. Regularity is one of its dimensions. Involvement, perseverance and carrying out responsibilities could also be regarded as attributes of discipline. Associate workers of a person who manages to keep oneself systematic and organized react according to latter's style of functioning, in order to meet the requirements of his objectives and expectations and extend their total voluntary support.

\subsubsection{No humiliation}

One naturally feels annoyed in finding irregularities in work or in irresponsible behavior of other persons. Nevertheless, on such occasions displeasure may not be expressed in a manner to humiliate the worker, which would, instead of reformation, make the accusation an issue of personal prestige and instigate arrogant defiance. This two-fold damage can be avoided if the defaulter is praised for some of his past good deeds and surprise is expressed for the present inadvertence, so that the guilty person feels ashamed of the mistake. Such a policy creates an environment for rectification of current errors.

\subsubsection{No strong likes and dislikes}

A good man must not have traits of strong likes and dislikes. It is pragmatic to follow the middle course. Whenever one deviates from this moderation of civility, and adopts extreme attitudes, one becomes exposed to undesirable pressures. By avoiding this weakness one can easily escape many embarrassing situations. Greatness lies in cultivating a habit of keeping one's own self as well as others free of tensions. It is not in the least desirable to become disturbed or agitated even in moments of least provocation or unfavorable circumstances. Nor is it good to boast in the event of achievements, however significant they may be. Only on developing such poise does one succeed in finding means for counteracting adversities and making circumstances favorable with renewed vigor. An excited person loses sense of reasoning and aggravates the misery by irresponsible behavior and actions.

\subsubsection{Intolerance against weakness and undesirable traits}

One should also adopt a policy of intolerance against weakness and undesirable traits and never lose an opportunity to express displeasure against the same. When indifference is shown towards irregularities in the initial stages, the defaulters begin to treat them as a matter of right and having become accustomed to that in course of time, consider any resistance against them as unfair and unjust. Unless reprimanded in time, a defaulter also attempts to seek an excuse behind the shield of others who were not punished for similar acts. For this very reason it is necessary to keep on praising the righteous and reproaching the careless persons. An efficient manager understands the necessity of timely encouragement and rapprochements for improvements and refinement in the system. Nevertheless a general atmosphere of friendliness and cordiality should also be maintained. With it, people tend to disregard past differences and remain faithful to the organization because of their conviction in the benevolence of the employer.

A rift is often created between persons because of misunderstandings. The differences arise more because of imaginary than real apprehensions. Hence, wherever such estrangement grows, an attempt should be made to find solution either directly or through the help of intermediaries. In order to nip possibilities of misunderstanding in the bud, organizational skill necessitates a continuous endeavor to keep the associated persons aware of real state of affairs. If the members of the family could be convinced that responsible behavior 
and faith result in personal progress and advantage, the former would not fall a prey to foreign forces of alienation.

\subsubsection{Equanimity}

From time to time one comes across unfavorable circumstances and frequently meets persons whose behavior does not conform to one's temperament. Nevertheless it should in no way disturb one's equanimity. One must maintain a positive attitude and look for a silver lining in each could. Instead of crying over the spilt milk one should think of ways and means to make amends for the loss. One must patiently wait for appropriate opportunities to sink the differences, befriend the alienated and regain the lost trust. It does not mean succumbing to injustice and encouraging undesirable elements by adopting a policy of appeasement. Rather cultivation of such an attitude of mind becomes necessary to restrain one's thinking form becoming defeatist, antagonistic or aggressive. A policy influenced by jealously, revenge and counteraction may appear indicative of strength, but it ultimately gives rise to a series of counteractive intrigues, which involve not only loss of energy but ultimately produce such results, which may appear as an advantage over the adversary, but are antithesis to what was intended. An efficient manager learns to organize one's own personal affairs and utilizes the experience so gained for management of other persons and their assignments. This in fact is the acid test of organizational skills, which every aspirant has to undergo (Sharma 2010).

\section{Conclusion}

In the world today, we are living through an age of confusions and tensions both within and without. The external challenges persecute us and render our lives unhappy and sorrow-ridden. The intelligent philosophy of the Rishis of Vedanta advises man 'to live in harmony' with the situations in life and steadily work on to meet them with discretion and constant application. When we live thus for a period of time, a subjective poise develops, giving us inward peace and tranquility, which, thereafter, remains unaffected by external threats and onslaughts. In the outer world of bitter competition and immoral strife, each one of us is compelled to battle constantly with things and beings. Deep within ourselves also, we have become helpless slaves to our own uncontrollable desires and undisciplined thoughts. Thus, modern man comes to shreds and is torn asunder between the two forces: the objective tensions and the subjective confusions.

The aim of organizational skills in Vedantic perspective is to learn how to better manage the inner organization as a means for more effective leadership of the external organization and develop a practical selfmanagement plan so that one can get the best out of oneself and others too. There has traditionally been a view of management that if one could manage the external environment then one could manage the change successfully. But the experience is that it is not always possible to manage the changes successfully from the external environment but there is a need to change the internal i.e. harnessing our inner resources which we have so far tended to neglect. We can consciously create our future on the basis of guiding values and a focused vision of the future. Today we have lost our mastery over ourselves. In our preoccupation with conquering nature and subduing her to serve us, we have ignored our own inner monstrosities. We have left our subtler perceptions undeveloped, and naturally, like a long-neglected garden, our inner world has grown into a jungle. We live in the outer world, but prompted from our own within. Our character and personality determine the experiences that we gain in the outer world. Unless we learn to master our inner life, the outer scheme of life, however efficient and perfect, cannot but bring sorrow and unhappiness to employees and in turn their organization.

\section{References}

Agarwal,Sunil. (2004). Success vs joy, New Delhi: 20:20 Media.

Bain, Neville. (1995). Successful management, England: Macmillan Business.

Batra, Vijay. (2008). The Success Guide, New Delhi: Think INC.

Chakravarty, Ajanta E. (1995), The Geeta and the art of successful management, New Delhi: HarperCollins Publishers.

Chinmayananda,Swami. (2006). Kindle life, Mumbai: Central Chinmaya Mission Trust.

Chinmayananda,Swami. (2003). Practice of vedanta, Mumbai: Central Chinmaya Mission Trust.

Chinmayananda,Swami. (2001). Vedanta in action, Mumbai: Central Chinmaya Mission Trust.

Chopra, Deepak. (1997), The path to love, London: Rider.

Freud,Sigmund. (1949). An outline of psychoanalysis, New York: m. p.

Gaur, Vidhu. (2012). Role of Inner Attributes in Improving Productivity, Sixth International Conference on Contemporary Business 2012 convened by IIT Delhi \& Curtin University, Australia, A Refereed International Conference, Delhi: IIT. Oct. 18-20, 2012.

Gaur, Vidhu. (2012). Vedantic Approach to Management Theory, IJEMT, Vol 2, October - March, 2011-12.

Ishwarananda, Swami. (1980). Towards fulfillment, Ahmedabad: Samvit Sadhanayana.

Kalra, J. B. (2010). Self motivation: management and motivating concept, Delhi: M. S. Marknet, pp. 127-190.

McGinnis, Alan Loy. (1998), The balanced life, Mumbai: Better Yourself Books. 
Mellowship, Dawn. (1997), You can only achieve what is possible, Bhopal: Indra Publishing House, pp. 1-213.

Parkinson, C. Northcote, M. K. Rustomji, and S. A. Sapre. (1999), Great ideas in management, New Delhi: Vision Books, pp. 1-214.

Radhakrishnan, S. (1988). Eastern religions and western thoughts, Delhi: Oxford University Press.

Ramsukh, Das Swami. (1986). Let us know the Truth, Delhi: Radha Press, pp. 1-91.

Reynolds Helen \& Mary E. Tramel. (1999), Executive time management, Delhi: Jaico Publishing House, pp. 1170.

Sadri, Sorab, Dhun S. Dastoor, and S. Jayashree. (2001). The theory and practice of managerial ethics, Mumbai: Jaico Publishing House, pp. 1-425.

Sharma, G. D. (2001), Management and the Indian ethos, New Delhi: Rupa \& Co., pp. 1-113.

Sharma,Shriram. (2011). Dignity of organizational skills, Mathura: Yug Nirman Yojana Trust, pp. 1-48.

Sharma,Shriram. (2011). Extrasensory potentials of the mind, Mathura: Yug Nirman Yojana Trust, pp. 1-246.

Sharma, Robin. (2006). Who will cry when you die? Delhi: Jaico Publishing House.

Sukh, Shammi. (2001). How to improve productivity for greater profits, Mumbai: Better Yourself Books, pp. $37-$ 115.

Tejguru, Sirshree. (2007). Self encounter: transformation, New Delhi: Macmillan.

Tejguru, Sirshree. (2009). How to be ever successful, Pune: Tej Gyan Foundation, pp. 9-18.

Tejomayananda, Swami. (2003). Right thinking, Mumbai: Central Chinmaya Mission Trust.

Tirtha, Swami Rama. (1978). In woods of God realization - Vol. ii, Lucknow: Rama Tirtha Pratisthan.

Usha,Sis. B. K. (2002). Self managing leadership, Brahma Kumari’s, Mt. Abu: Literature Dept., pp. 1-125.

Vivekananda, Swami. (1996). Practical vedanta, Calcutta: Advaita Ashrama.

Waite, Rob. (2009). The lost art of general management: life skills, Bhopal: Indra Publishing House, pp. 93-120.

Wicks, J. Robert. (1999). Living a gentle passionate life, Mumbai: Better Yourself Books.

\section{Biography}

Author, Dr. Vidhu Gaur, holds degrees of PhD, MBA and PGDCM. She is a certified Soft Skill Trainer and a life member of Indian Society of Training \& Development, Bangalore chapter. She is currently working as an Assistant Professor at MDI Gurgaon. She has both critical and creative writings to her credit published in esteemed journals and leading newspapers. Her main areas of interest and specialization include: Communication, Soft Skills, and Personal Effectiveness. As a professional speaker and corporate trainer she has motivated and educated hundreds of students of both academic and management fields and people of industry in various states of India.

\section{Acknowledgement}

I owe a debt of gratitude to Yug Nirman Yojana Vistar Trust, Gayatri Tapobhumi, Mathura for providing me their written consent through email for utilizing the matter of their publications in my research papers. My father, Shri Y. K. Gaur, has always been a source of constant inspiration to me. I am thankful to almighty to give me a beautiful daughter, Miss Vidita, seeing whose face I forget every work pressure and feel encouraged to read and write articles. 
The IISTE is a pioneer in the Open-Access hosting service and academic event management. The aim of the firm is Accelerating Global Knowledge Sharing.

More information about the firm can be found on the homepage:

http://www.iiste.org

\section{CALL FOR JOURNAL PAPERS}

There are more than 30 peer-reviewed academic journals hosted under the hosting platform.

Prospective authors of journals can find the submission instruction on the following page: http://www.iiste.org/journals/ All the journals articles are available online to the readers all over the world without financial, legal, or technical barriers other than those inseparable from gaining access to the internet itself. Paper version of the journals is also available upon request of readers and authors.

\section{MORE RESOURCES}

Book publication information: http://www.iiste.org/book/

Academic conference: http://www.iiste.org/conference/upcoming-conferences-call-for-paper/

\section{IISTE Knowledge Sharing Partners}

EBSCO, Index Copernicus, Ulrich's Periodicals Directory, JournalTOCS, PKP Open Archives Harvester, Bielefeld Academic Search Engine, Elektronische Zeitschriftenbibliothek EZB, Open J-Gate, OCLC WorldCat, Universe Digtial Library, NewJour, Google Scholar

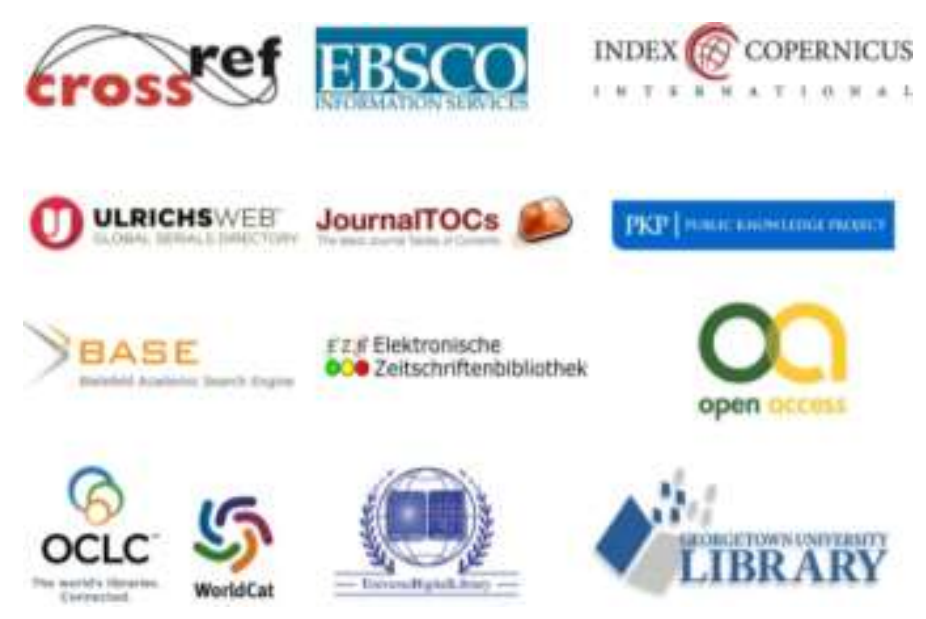

